\title{
Entrevista Prof. Dr. Cleverson Vitório Andreoli
}

\author{
Por Norman Arruda Filho', Kathya Balan ${ }^{2}$ \\ Recebido: 16/09/2020. Aceito: 24/09/2020
}

\section{Apresentação}

Na última década, a abertura de novos cursos de mestrado profissional no Brasil cresceu vertiginosamente. Em 2007, a CAPES tinha registrado 184 cursos, em 2017 já havia 771. Regulamentado no Brasil há aproximadamente 20 anos, o mestrado profissional oferece ao aluno a possibilidade de realizar uma pesquisa, desenvolvida com o mesmo rigor teórico do mestrado acadêmico, e aplicá-la na prática em seu âmbito profissional.

No Brasil, na década de 1960 existia a necessidade da busca por docentes qualificados e desta forma ocorreu o incentivo ao mestrado acadêmico. Porém, a falta de aplicabilidade das pesquisas fez com que o Brasil ficasse "atrás" de países mais desenvolvidos que investem em inovação e pesquisas aplicadas ao desenvolvimento de negócios, produtos e serviços.

No ISAE Escola de Negócios, o Programa de Mestrado Profissional em Governança e Sustentabilidade foi criado em 2013. Reconhecido e recomendado pela CAPES, possui o objetivo de oferecer um curso de mestrado que estimule a produção de conhecimento aplicado em temas atuais, tais como Desenvolvimento Sustentável, Governança Organizacional, Governança Pública, Gestão de Riscos e Desastres, Inovação, Sustentabilidade e Tecnologias Ambientais. Seguindo as diretrizes dos Objetivos de Desenvolvimento Sustentável - ODS e os Princípios para Educação Empresarial Responsável - PRME, foi o primeiro mestrado do Brasil a abordar estas temáticas, com o objetivo de formar lideranças que promovam a governança responsável, a sustentabilidade corporativa, com foco na solução dos problemas socioambientais decorrentes da crise civilizatória vigente.

Com 119 mestres formados, as pesquisas desenvolvidas no Programa já foram aplicadas em instituições como Copel, Sanepar, Tribunal Regional Eleitoral de São José dos Pinhais, Instituto Municipal de Administração de Curitiba, entre outras. Nesse contexto, o nosso convidado para a entrevista desta edição é o professor Dr. Cleverson Vitório Andreoli, que irá nos explicar sobre a dinâmica do mestrado profissional no Brasil.

Cleverson Vitório Andreoli é engenheiro agrônomo formado pela Universidade Federal do Paraná UFPR em 1982, mestre em Ciência do Solo pela UFPR e doutor em Meio Ambiente e Desenvolvimento pela UFPR, em 1998.

Em sua trajetória profissional desempenhou o cargo de Superintendente da SUREHMA - Agência Ambiental do Paraná e foi também fundador e presidente do Núcleo Interdisciplinar de Meio Ambiente e Desen-

1 Presidente do Instituto Superior de Administração e Economia do Mercosul - ISAE. E-mail: norman@isaebrasil.com.br

2 Mestranda do Programa de Pós-Graduação em Governança e Sustentabilidade - PPGS (ISAE). E-mail: kathya.balan@isaebrasil. com.br 
volvimento - NIMAD da Universidade Federal do Paraná, quando foi criado o Programa de Doutorado em Meio Ambiente e Desenvolvimento em cooperação com universidades francesas. Foi presidente da Associação Brasileira de Entidades de Meio Ambiente - ABEMA, entidade que congrega todas as agências ambientais dos estados brasileiros e da Seção Brasileira da International Association for Impact Assessment. Foi ainda representante do Paraná no Conselho Nacional de Meio Ambiente - CONAMA, de onde recebeu uma moção de reconhecimento pela defesa da causa ambiental brasileira, aprovada por unanimidade pelos seus 54 membros.

Membro da Academia Internacional de Águas com sede em Oslo/Noruega, realizou diversas consultorias para entidades internacionais como o Programa das Nações Unidas para o Meio Ambiente - PNUMA, o Programa das Nações Unidas para o Desenvolvimento - PNUD e a Organização das Nações Unidas para Alimentação e a Agricultura - FAO, na área de gestão ambiental e recursos hídricos.

Andreoli atuou com empresas de Saneamento no Paraná, Tocantins Espírito Santo, Santa Catarina e Mato Grosso, na área de gestão de resíduos, e nas secretarias de Meio ambiente do município de Vitória, e dos estados do Mato Grosso e Mato Grosso do Sul, na área de gestão ambiental e avaliação de impacto ambiental.

Prestou consultorias ao Instituto Brasileiro do Meio Ambiente e dos Recursos Naturais Renováveis IBAMA, na área de gestão ambiental e licenciamento ambiental nos estados do Sul e em São Paulo. Autor de mais de 190 artigos científicos publicados em revistas cientificas e congressos, publicou 27 livros técnicos nas áreas de gestão ambiental, gerenciamento de resíduos e de educação ambiental. Participou de programas de cooperação técnica internacional na área de disposição final de lodo de esgoto, com visitas a França, junto à empresa Agrodevelopmment, e aos Estados Unidos, na Ohio State University, além de participar de seminários na França, Estados Unidos, Grécia, Uruguai, Chile, Argentina e República Dominicana. Palestrante reconhecido nacional e internacionalmente, Cleverson Andreoli é professor do mestrado ISAE e de outras instituições de ensino superior, e sócio-diretor e fundador da CEa - Consultoria e Engenharia Ambiental Ltda.

\section{Professor, qual a diferença básica entre o Mestrado Profissional e o Mestrado Acadêmico?}

A pós-graduação é classificada em latu sensu, que são as especializações e os MBAs, e em stricto sensu, que são os mestrados e doutorados acadêmicos ou profissionais. Os cursos latu sensu geralmente são voltados para apresentar, aprofundar e capacitar o aluno a utilizar uma ferramenta específica já testada e utilizada na sociedade. O trabalho de conclusão de curso é uma monografia, que é uma aplicação desta ferramenta em um caso específico ou mesmo uma análise sobre a sua aplicação. Os cursos de mestrado e doutorado acadêmico exigem que o aluno, utilizando o método científico, desenvolva uma inovação no conhecimento, que no caso do doutorado, deve ser inédita. O mestrado profissional exige que o estudo desenvolvido produza um "produto técnico", que deve ter aplicabilidade prática.

Basicamente, o aluno de um mestrado profissional deve ter a capacidade de adotar o método cientifico para desenvolver uma solução a um problema prático, aplicável na sua área de atuação ou empresa. A origem do conceito de mestrado profissional foi a ideia de que a pesquisa exigida para a conclusão do curso atendesse mais diretamente as necessidades do mercado. 


\section{Qual seu ponto de vista sobre o crescimento dos cursos de Mestrado Profissional no Brasil?}

São bem conhecidas as graves deficiências do sistema educacional brasileiro, que determina em grande parte os maiores problemas nacionais, como a baixa produtividade do trabalho, a inaceitável concentração de riquezas e até mesmo o quadro político deteriorado, pela escolha frequente de péssimos representantes no legislativo e executivo. Uma população com baixo grau de escolaridade é facilmente manipulada por políticos populistas, que se revezam no poder, com raras e honrosas exceções.

Com a ampliação ao acesso a informação e a velocidade do avanço da inovação tecnológica, o processo de formação não acaba nunca. O sistema educacional não tem mais apenas a obrigação de repassar o conhecimento, mas principalmente de ensinar os alunos a buscar a informação e aprender de forma autônoma, pois na realidade atual da sociedade, quem não se mantem atualizado fica rapidamente obsoleto.

Os cursos de pós-graduação, especialmente o stricto sensu capacitam o aluno a adotar o método cientifico, que pode ser utilizado para o enfrentamento de qualquer tipo de problema, não apenas sob o ponto de vista teórico, mas também aqueles enfrentados no dia a dia das empresas. A busca de novas soluções é o único caminho para um desenvolvimento consistente da economia.

Por estas razões, há anos já é muito comum no mundo desenvolvido, que os cargos estratégicos sejam ocupados por profissionais capacitados ao processo de inovação tecnológica. Consequentemente o mercado de trabalho valoriza muito a formação no stricto sensu ou profissionais que tiveram a capacidade de desenvolver esta competência na sua vida profissional. No Brasil, este tipo de formação era exigido apenas para profissionais da academia, posteriormente passou a ser valorizado em concursos públicos e para pontuação em editais de licitação. Atualmente, se observa que as empresas privadas já entenderam os diferenciais que este tipo de formação trás para as empresas e, cada vez mais, não apenas jovens que estão se capacitando para ocupar este novo espaço no mercado de trabalho, mas, principalmente, pessoas com posições estratégicas nas empresas buscam os mestrados para se manter atualizados para consolidar as suas carreiras para o futuro.

\section{Como o senhor encara a posição do Brasil em relação aos países mais desenvolvidos sobre o desenvolvi- mento de pesquisas aplicadas?}

Até as últimas décadas do século passado, se entendia que havia uma divisão entre primeiro mundo, que fornecia produtos tecnológicos, o segundo mundo formado pelos países socialistas e o terceiro mundo que fornecia commodities, principalmente, matéria-prima mineral ou produtos agrícolas primários para abastecer a indústria de transformação.

Uma transformação radical destes conceitos foi imposta nos últimos anos, pelo grande aumento da velocidade da produção do conhecimento e da decorrente revolução determinada pela inovação tecnológica.

Hoje, o primeiro mundo produz conhecimento e grande parte da indústria de transformação migrou para países onde a mão de obra era mais barata. O que é muito bem remunerado no mercado internacional são os projetos, as novas ideias, as inovações ficando a sua execução terceirizada para países onde o custo de produção é mais baixo. No Brasil, o grande custo das leis trabalhistas dificultou muito a aproveitar essa migração e, 
consequentemente, nos mantemos como país fornecedor de matérias-primas.

Além disso, outro importante fator manteve e mantem a indústria nacional em marcha lenta: a dependência tecnológica. Ainda convivemos em nosso país com um grande preconceito de pesquisadores em relação ao mercado e do mercado em relação aos pesquisadores. Por esta razão, grande parte do conhecimento produzido nas universidades, principalmente, nas públicas que são responsáveis pela maior parte da produção científica, fica restrito a papers acadêmicos, muitas vezes descolados do meio produtivo, que não chegam ao seu objetivo final, que é melhorar as condições da humanidade. Nos últimos anos, verificou-se um grande incremento da produção científica nacional e um movimento para transformar o conhecimento científico gerado em inovação tecnológica, que exige a sua aplicação prática, no entanto, é necessário intensificar este processo. A grande exceção é o agronegócio, que por uma importante influência da EMBRAPA, evoluiu tecnologicamente, fazendo do Brasil um dos principais polos de conhecimento e produção na área agrosilvopastoril. Os resultados econômicos e sociais provenientes do agronegócio já demostram a grande importância da adoção de novos métodos e técnicas desenvolvidas dentro da realidade brasileira. Além dos grandes benefícios para a economia, a agricultura brasileira é uma das mais sustentáveis do mundo. É claro que a agricultura brasileira tem muito a evoluir em relação a sustentabilidade, contudo, grande parte do discurso que demoniza o agronegócio, não passa de uma estratégia sórdida para criar barreiras comerciais aos produtos aqui produzidos.

Por estas razões a aproximação da academia com o setor produtivo, trarão grandes benefícios econômicos, sociais e ambientais, que representa um forte fator indutor ao desenvolvimento sustentável em nosso país, o que justifica o impressionante crescimento dos cursos de mestrado e doutorado. Aqueles que se anteciparem a tendência do mercado, tanto profissionais como empresas, vão ser beneficiados e se consolidar na vanguarda do desenvolvimento nacional.

\section{O senhor poderia nos apresentar algum caso bem-sucedido de pesquisa desenvolvida no ISAE e aplica- da no mercado?}

A maior parte das dissertações do mestrado profissional em Governança e Sustentabilidade do ISAE são diretamente ligadas à solução de problemas das empresas nas quais os alunos estão vinculados. Podemos destacar alguns casos como exemplos, sem desmerecer os demais.

Uma pesquisa desenvolveu a proposta de um modelo de gestão de Shopping Center, que tenha como base os ODS, a fim de verificar o nível de engajamento observado nos Shoppings com relação às práticas de sustentabilidade nos empreendimentos. O modelo apresentado, com base em dados de 40 empreendimentos de uma administradora brasileira, caracteriza-se como uma ferramenta de fácil adesão e reflete a tendência dos novos empreendimentos aderirem as dimensões da sustentabilidade. Os resultados da verificação da aplicação do modelo em dois empreendimentos, em fase de implantação revela que a empresa tem buscado inserir inovações nos aspectos ambientais, sociais em seu novo empreendimento e que estas foram percebidas pelo modelo. Este sistema foi adotado por todos os empreendimentos controlados pela empresa nos mais de 40 shoppings em todo o Brasil e, por meio dos resultados apresentados, a mestra assumiu a posição de gerente 
da empresa.

Outra dissertação fez a avaliação dos diferentes tipos de falhas de qualidade na madeira serrada, do controle da qualidade e sua influência no valor do produto final, com a implementação de planos de melhoria através da ferramenta de melhoria continua Kaizen. Após a implantação dos procedimentos definidos na pesquisa, foi auferida a estimativa de perda econômica nos comparativos dos dois períodos, antes e depois das intervenções, que calculou um prejuízo evitado de US\$ $383.817,00$, já no primeiro ano de aplicação dos resultados da pesquisa.

Finalmente, podemos apresentar uma dissertação que teve como objetivo propor uma metodologia para o ensino da Biologia como potencial ferramenta de apoio para o alcance dos Objetivos de Desenvolvimento Sustentável. Foram desenvolvidos três app-books (Tecnologias Digitais de Informação e Comunicação - TDIC), cada um associado a um ODS, que foram apoiados em contos literários universais e possuem atividades de reflexão, experimento científico e ação social. O primeiro app-book desenvolvido foi Frritt-Flacc, conectado ao ODS 1: Erradicação da Pobreza. O segundo app-book foi Ostras, do conto de mesmo nome do escritor Anton Chekhov, correspondente ao ODS 2 - Fome Zero e Agricultura Sustentável, e o terceiro app-book desenvolvido foi o Rei do Rio de Ouro, do conto do escritor John Ruskin, ligado ao ODS 6: Água Limpa e Saneamento. Apenas o app-book Frritt-Flacc pôde ser testado. O potencial alcance de impacto da aplicação prática da pesquisa é de mais de 167.550 mil pessoas na América Latina até 2020. 